\title{
Investigating the self-study phase of an inverted biochemistry classroom - collaborative dyadic learning makes the difference
}

Susanne J. Kühl ${ }^{1 *}$ (D) Achim Schneider ${ }^{1,2}$, Hans A. Kestler ${ }^{3}$, Matthias Toberer ${ }^{1}$, Michael Kühl' and Martin R. Fischer ${ }^{4}$

\begin{abstract}
Background: The inverted classroom approach is characterized by a primary self-study phase for students followed by an on-site, face-to-face teaching phase that is used to deepen the prior acquired knowledge. Obviously, this teaching approach relies on the students preparing before the on-site phase, which in turn requires optimized preparatory material as well as defined working instructions. The major aim of this study, therefore, was to investigate the effect of different preparatory materials and working instructions for the self-study phase of an elearning-based inverted classroom on the knowledge gained by medical students in biochemistry. Furthermore, we analyzed whether collaborative dyadic learning during the self-study phase is more effective than individual learning with respect to knowledge gain.

Methods: The study was performed in a biochemistry seminar for second semester medical students at Ulm University in Germany. This seminar was held using an e-learning-based inverted classroom. A total of 196 students were divided into three homogeneous study groups that differed in terms of the working material and instructions provided for the self-study phase. Knowledge gain was measured by formative tests at the beginning of the on-site phases. Questionnaires were also handed out asking about motivation, interest and learning time in the self-study phases.
\end{abstract}

Results: Students who were told to prepare in collaborating dyads during the self-study phase performed better in formative tests taken at the beginning of on-site phases than learners who were told to prepare individually. The study material that was provided was of minor importance for the differences in formative testing since almost all students prepared for the on-site phases. With the dyadic learning approach, both students benefited from this collaboration, characterized by a higher motivation and interest in the topic, as well as a longer time spent on task.

Conclusion: Our study provides strong evidence that the study material, but more importantly the instructions provided for the self-study phase, affect students` knowledge gain in an e-learning-based inverted classroom. The instructed collaboratively working group was the most successful.

Keywords: Inverted classroom, Flipped classroom, Self-study phase, Medical course of studies, Biochemistry, Collaborative learning

\footnotetext{
* Correspondence: susanne.kuehl@uni-ulm.de

${ }^{1}$ Institute of Biochemistry and Molecular Biology, Ulm University,

Albert-Einstein-Allee 11, 89081 Ulm, Germany

Full list of author information is available at the end of the article
}

(c) The Author(s). 2019 Open Access This article is distributed under the terms of the Creative Commons Attribution 4.0 International License (http://creativecommons.org/licenses/by/4.0/), which permits unrestricted use, distribution, and reproduction in any medium, provided you give appropriate credit to the original author(s) and the source, provide a link to the Creative Commons license, and indicate if changes were made. The Creative Commons Public Domain Dedication waiver (http://creativecommons.org/publicdomain/zero/1.0/) applies to the data made available in this article, unless otherwise stated. 


\section{Background}

The Inverted Classroom (IC) is a state-of-the-art teaching method based largely on a blended learning approach and is characterized by two distinct phases $[1,2]$. In the primary self-study phase, students prepare a certain subject matter on their own followed by an on-site phase in which learners apply the acquired knowledge in a group of students under the supervision of a lecturer. The advantage of this method is that the learning material is initially appropriated in the self-study phase, which creates more free time in the following on-site phase. This freed-up time in the on-site phase can be used to apply the prepared learning matter in a more suitable manner. As a result, passive knowledge is transferred into more active knowledge, resulting in a higher level of learning. Moreover, additional competencies can be gained during the on-site phase [3].

Initial studies have rated the IC method as being conducive to learning [4]. The IC method has already been put to successful use in different fields such as medical studies, dentistry, pharmaceutics, nursing as well as other healthcare professions and has been described as a meaningful teaching approach [5-17]. In previous studies, we and others have observed that students were more motivated and satisfied with the IC method than with traditional teaching methods [3, 17-20].

The IC method can only be implemented successfully if the students prepare for the on-site phase in the initial self-study phase. The better the students prepare, the more effective the method becomes. If students do not prepare, subject matters cannot be applied in the on-site phase. Thus, special attention should be paid to the preparatory material for the students and to the instructions for the self-study phase. We suggested implementing the IC approach with an e-learning-based self-study phase since computer-based learning has become a relatively familiar and well-accepted mode of education for students [3]. This is substantiated by other studies that show a high preference amongst students for digital media compared to non-digital learning resources in a pharmacology course [21]. Furthermore, medical students preferred to learn using computer-aided course instructions instead of paper workbooks in a physiology course [22].

For many years, learning in a group has been described as an effective learning method [23-25]. It has been shown that collaborative learning increases the learning success for cognitive and affective learning objectives, and increases the social competence of learners $[26,27]$. Moreover, collaborative learning approaches can have a positive effect on the learner's intrinsic motivation and internal attitude when it comes to learning certain subjects. It has also been reported that learners benefit from learning in smaller groups [28]. Guidelines on how to structure a computer-based, interactive process through learning partners have already been published [29, 30]. But little information is as yet available on the use and efficacy of collaborative, computer-based learning in the self-study phase of an IC. Moreover, the influence of different learning materials and instructions on a student's learning success in an IC has not yet been investigated in detail.

The main aim of this study was to analyze the influence of the instruction and study material provided for the self-study phase of an e-learning-based inverted classroom on the knowledge gain of medical students in the field of biochemistry. In particular, we investigated whether collaborative learning dyads of students in the self-study phase achieve higher conceptual and/or conditional knowledge in comparison to individual learners.

\section{Methods}

\section{Course description}

The study was performed in a biochemistry seminar entitled "From gene to protein", as part of the so-called Integrated Seminar. This is a compulsory course for all medical students in Germany in the pre-clinical stage of their studies. In Ulm, this particular course is held in the second semester. The course comprises two appointments (on-site phases 1 and 2) of four hours each. Furthermore, students have to prepare for the appointments (self-study phases 1 and 2). All students are assigned to classes and each class consists of about 20 students.

\section{Participants in the study and classification}

During the summer semester 2017 at Ulm University, $196 \mathrm{~s}$ semester medical students participated in this study. Not all of the students completed all of the voluntary questionnaires or took part in the knowledge tests of this study. The exact numbers of individual students who answered particular questionnaires are shown in the legend for each figure or table.

Students are generally assigned to classes by the Office of Student Affairs of the Medical Faculty Ulm for this seminar. This is a random group allocation without any influence from the lecturers. Some students only swap groups so that they can attend other elective subjects.

\section{Study design and instructions for self-study phases}

To investigate the influence of the working material and the instructions provided for the self-study phases, we created three random study groups (see Fig. 1). These groups differed in the study material provided for the self-study phases and the accompanying instructions (including the on-site phase 0 ). Two classes with 42 students in total were assigned at random to the basic group, four classes with 76 students in total to the individual and four classes with 78 students in total to the 


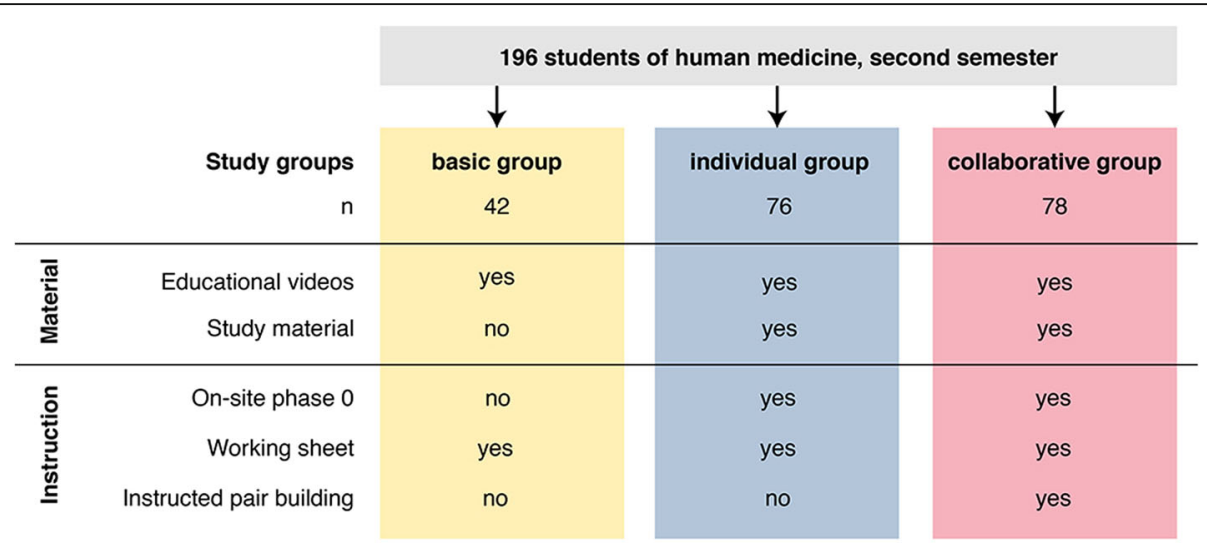

Fig. 1 Overview of the independent variables for the different study groups. In summary, 196 medical students from Ulm University participated in this study. The study was carried out in the second semester in a pre-clinical biochemistry seminar. Yellow: students in the basic group $(n=$ 42) received an information e-mail in which they were told to watch three videos until on-site phase 1 (working sheet basic group). For self-study phase 2, students in the basic group were told to watch two videos. They were neither instructed to form learning dyads, nor did they receive any comprehension questions. Blue: 76 students were in the individual group. After an information e-mail, they started with an on-site phase 0. They received instructions and a working sheet (working sheet individual group) for self-study phase 1. Most importantly, they were told to prepare alone in self-study phase 1. Self-study phase 1 was characterized by watching videos and dealing with comprehension questions as provided in the study material. Self-study phase 2 was similar to self-study phase 1. Red: 78 students were in the collaborative group. The study procedure for the collaborative group was the same as that of the individual group, except they were told to prepare in learning dyads during the self-study phases

collaborative dyad group. Questionnaires on the sociodemographic characteristics of participants (sex, age and semester) and prior knowledge (grades of the final secondary-school examinations and the exams in the first semester such as anatomy, biology, terminology, chemistry and physics) were used to check for homogeneous study groups. Furthermore, a questionnaire was used on students' motivation. All three study groups had access to the same educational videos and instructions to watch these videos before the following on-site phases.

The students in the basic group were briefed by an e-mail to study the three educational videos up to on-site phase 1 (instruction basic group). They received no additional study material with comprehension questions at all.

In an on-site phase 0 , both the individual and the collaborative group received additional study material for the self-study phase to support learning. Additionally, they were instructed to learn individually or in collaborative dyads. The students in the individual and collaborative group received worksheets with exact instructions on how to learn during the self-study phases in preparation for either on-site phase 1 or 2 . Whereas the students in the individual group were instructed to solve the comprehension questions on their own (instruction individual group), the students in the collaborative group were told to deal with the tasks from the self-study phases in cooperation with a learning partner of their own choice (instruction collaborative group). Learning dyads were created during on-site phase 0 when all of the students were present. Different worksheets were drawn up by S.J.K. and reviewed by two independent experts (M.K. and A.S).

Knowledge tests were taken immediately at the beginning of the on-site phases 1 and 2 to investigate the success of the prior preparation of students.

Additional file 1: Figure S1 and Additional file 2 provide a detailed outline of the study design with respect to the timing of actions (information about the IC method, questionnaires and tests). A total of four teachers were involved in teaching during the on-site phases, whereas one lecturer (S.J.K.) was responsible for providing instruction for all three study groups.

\section{Material for the self-study phases: educational videos and associated study material}

The three educational videos for self-study phase 1 had already been used in our previous study and include the following topics: protein biosynthesis in general (transcription and translation at the ribosome), protein biosynthesis into the rough endoplasmatic reticulum and the subsequent vesicle transport as well as the structure and formation of the collagen triple helix and fibrils [3]. The two educational videos for self-study phase 2 present two biochemical methods: SDS-PAGE (sodiumdodecylsulfate polyacrylamide gelelectrophoresis) and DNA sequencing. All of the educational videos are available from the Institute of Biochemistry and Molecular Biology at Ulm University.

Additional printed study material with eleven (self-vstudy phase 1) and four (self-study phase 2) 
comprehension questions were provided as a self-study assessment for the individual and collaborative learners. Questions regarding conceptual and conditional knowledge were integrated into the material for each self-study phase. Whereas the comprehension questions in self-study phase 1 only asked for biochemical basics, the study material for self-study phase 2 began with a clinical case report and included one question based on this case. Half of the comprehension questions had already been used in the same seminar the previous year [3]. All of the comprehension questions were drawn up by S.J.K. and reviewed by four independent experts, one internal (M.K, Ulm University) and two external biochemical experts (Universities of Frankfurt and Würzburg, Germany) as well as one psychologist (A.S., Ulm University).

\section{Ethics and consent}

The ethics committee of Ulm University confirmed that no approval was required for this study. Students were verbally informed by a power point presentation during the first on-site phase that all tests and questionnaires were voluntary and anonymous. Students were informed that by handing in the questionnaires, they automatically gave their informed consent. No fees were paid for participation in this study.

\section{Data collection}

Participation in all questionnaires and knowledge tests was voluntary and anonymous. Since one student refused any active involvement in the study, the questionnaires and tests for this person were removed from the study. In addition, because a few statements within the remaining questionnaires were contradictory, a double check was performed on these statements. Statements where no definite attribution was possible were classified as missing, excluded from analyses and therefore led to minor variations in sample sizes (see Figures and tables for the exact number of tests $(\mathrm{n}))$.

\section{Determination of knowledge gain}

To test the acquisition of knowledge in the self-study phases, formative, written tests were held at the beginning of on-site phase 1 and 2. These tests asked about the content of the self-study phases and had to be answered individually. The tests included questions about conceptual (multiple choice questions) and conditional knowledge (problem-solving questions; [31, 32]). Multiple-choice questions of type $A_{p o s}$ (choose one correct answer from five possible answers), $A_{\text {neg }}$ (choose one incorrect answer from five possible answers) and $K_{\text {prim }}$ (decide for each statement whether it is correct or not) and the competency levels 1 (remembering), 2 (understanding) and 3 (applying) of the Bloom taxonomy were asked for the conceptual knowledge [33, 34]. Problem-solving tasks were asked and students had to write free-text answers for the conditional knowledge. Competency level 4 (evaluate) was reached through these problem-solving questions. Part of the knowledge test 1 had already been used with other students the previous year and had worked well [3]. Both knowledge tests were prepared by a biochemical expert (S.J.K.) and reviewed by four independent experts, one internal (M.K, Ulm University) and two external biochemical experts (Universities of Frankfurt and Würzburg, Germany) as well as one psychologist (A.S., Ulm University). Since the questions for conditional knowledge were answered by the participants with free texts, the responses were rated manually using an expert solution. Rating for all conditional questions was performed by one biochemical expert (S.J.K.) and cross-checked by a second one (M.K.).

\section{Questionnaires about motivation, interest and learning behavior}

In order to analyze the students' motivation and interest in the material of the self-study phases, questionnaires were issued at the beginning of on-site phases 1 and 2 (second and third data collection). Students were also asked whether they understood the relevance of the material in the self-study phases. All of these questions were rated on a Likert-scale from 1 (strongly disagree) to 6 (strongly agree). The students were also asked about their learning behavior (individual or collaborative learning, learning period, preparation done or not). All questionnaires were drawn up by S.J.K. and reviewed by two independent experts (M.K. and A.S).

\section{Data analyses and statistics}

We conducted an a priori estimation of sample size for all effects we wanted to investigate. A medium effect size of $\mathrm{d}=0.6$ was assumed for these calculations, power was set to $80 \%$ and alpha was set to $5 \%$. The estimated number of total participants was $n=111$, translating into $n=37$ for each group respectively. Comparisons of sociodemographic data were carried out between groups with Chi-squared tests for sex and with ANOVAs for age, semester and grades. Analyses of the preparatory material and interest in the self-study phases of the inverted classroom were carried out with ANOVAs between groups, whereas Tukey-HSD was used for post hoc single comparisons. Analyses of the manner of preparation and time taken for the self-study phases of the inverted classroom were carried out with Kruskal-Wallis $\mathrm{H}$ tests, whereas Mann-Whitney $\mathrm{U}$ tests were used for post hoc single comparisons. The Mann-Whitney U test was also used to determine statistical differences in the knowledge tests. 
An assessment of pairs versus individual members was performed using a bootstrap procedure $\left(n=10^{6}\right)$ on the pairing of all individual participants (students of the individual group) and taking the performance of the more confident member as the pair's performance. Mean performance values were calculated and compared to the mean values of collaborative group [35].

A $p$-value of $<0.05$ was considered to be significant. Statistical significances are as indicated in the legends of all figures.

\section{Results}

\section{Study groups were homogeneous}

To analyze whether study groups were homogeneous with respect to their participants, socio-demographic data (sex, age, semester) and prior knowledge (grades in the final secondary-school examination and 1st semester) was collected for all study groups (Table 1). The data shows that the study groups did not differ significantly with respect to these factors. We also asked about the students' basic motivation and interest (Table 2). This data also indicated a motivation and interest similar to that for studying human medicine or learning biochemistry in the three groups, basic, individual and collaborative.

We therefore considered the different groups of this study to be homogeneous with regard to the tested factors.

\section{Students followed the instructions provided}

In order to examine the students' learning behavior in the self-study phases, we monitored how many students prepared for the on-site phases. In the basic group, $87.8 \%$ ( $n=36$ answers) watched the educational videos for self-study phase 1 and $100 \%$ ( $n=42$ answers) for self-study phase 2 . In the individual group, 100\% (self-study phase $1 ; n=76$ answers) and $98.6 \%$ (self-study phase 2, $n=73$ answers) prepared for the on-site phases. In the collaborative group, $96 \%$ (self-study phase $1 ; n=$ 72 answers) and 100\% (self-study phase $2 ; n=72$ answers) prepared for the on-site phases. In order to investigate the ecological validity, we verified compliance with the different instructions for the individual and collaborative group. We asked both groups how many students had learned collaboratively with a learning partner. In the individual group, 6.5\% (self-study phase 1) and $9.5 \%$ (self-study phase 2 ) had learned with a partner. In the collaborative group, $64 \%$ (self-study phase 1) and $58.7 \%$ (self-study phase 2 ) had prepared in a learning dyad as instructed.

This data indicates that nearly all students prepared prior to the on-site phase during the self-study phases and the majority followed the instructions as regards the learning behavior (individual vs. collaborative).

\section{Collaborative dyadic learning in the self-study phase leads to a better learning outcome}

In order to determine whether there was a difference in the learning outcome between the basic, individual and collaborative groups, a knowledge test was carried out at the beginning of on-site phases 1 and 2 respectively. Questions about conceptual (multiple choice questions) and conditional (free text, problem-solving questions) knowledge were integrated in both tests. These tests asked about the content of the self-study phases and had to be completed individually.

If we consider the results of both tests together (Fig. 2a), students in the collaborative group experienced a significantly higher acquisition of knowledge, divided equally between both conceptual and conditional

Table 1 Comparison between study groups

\begin{tabular}{|c|c|c|c|c|c|}
\hline & $\begin{array}{l}\text { Basic group } \\
\text { (SD) }\end{array}$ & $\begin{array}{l}\text { Individual group } \\
\text { (SD) }\end{array}$ & $\begin{array}{l}\text { Collaborative group } \\
\text { (SD) }\end{array}$ & $\begin{array}{l}\text { Total } \\
\text { (SD) }\end{array}$ & Group comparison \\
\hline$n$ & 42 & 76 & $72-75$ & $190-193$ & \\
\hline sex (female in \%) & 71.4 & 67.5 & 58.7 & 64.9 & $\begin{array}{l}\text { n. s. } \\
\left(\operatorname{chi}^{2}(2, N=193)=2.30, p=0.32\right)\end{array}$ \\
\hline age & $\begin{array}{l}21.6 \\
(3.37)\end{array}$ & $\begin{array}{l}21.35 \\
(3.28)\end{array}$ & $\begin{array}{l}21.76 \\
(3.99)\end{array}$ & $\begin{array}{l}21.56 \\
(3.57)\end{array}$ & $\begin{array}{l}\text { n. s. } \\
(F(2,190)=0.25, p=0.78)\end{array}$ \\
\hline semester & $\begin{array}{l}2.02 \\
(0.35)\end{array}$ & $\begin{array}{l}1.99 \\
(0.11)\end{array}$ & $\begin{array}{l}2.04 \\
(0.26)\end{array}$ & $\begin{array}{l}2.02 \\
(0.24)\end{array}$ & $\begin{array}{l}\text { n. S. } \\
(F(2,190)=0.97, p=0.38)\end{array}$ \\
\hline grade final secondary-school examination & $\begin{array}{l}1.48 \\
(0.43)\end{array}$ & $\begin{array}{l}1.51 \\
(0.47)\end{array}$ & $\begin{array}{l}1.58 \\
(0.50)\end{array}$ & $\begin{array}{l}1.53 \\
(0.47)\end{array}$ & $\begin{array}{l}\text { n. s. } \\
(F(2,187)=0.63, p=0.53)\end{array}$ \\
\hline grade exams 1st semester & $\begin{array}{l}2.38 \\
(0.80)\end{array}$ & $\begin{array}{l}2.31 \\
(0.55)\end{array}$ & $\begin{array}{l}2.30 \\
(0.65)\end{array}$ & $\begin{array}{l}2.32 \\
(0.65)\end{array}$ & $\begin{array}{l}\text { n. s. } \\
(F(2,187)=0.23, p=0.79)\end{array}$ \\
\hline
\end{tabular}

$n$, number of individual students, SD standard deviation, n.s. not significant. Between group comparisons were carried out with chi-squared test for sex and with ANOVAs for the other factors 
Table 2 Basic motivation and interest across different study groups

\begin{tabular}{|c|c|c|c|c|c|}
\hline Items about basic motivation and interest & $\begin{array}{l}\text { Basic group } \\
\text { (SD) }\end{array}$ & $\begin{array}{l}\text { Individual group } \\
\text { (SD) }\end{array}$ & $\begin{array}{l}\text { Collaborative group } \\
\text { (SD) }\end{array}$ & $\begin{array}{l}\text { Total } \\
\text { (SD) }\end{array}$ & Group comparison \\
\hline $\mathrm{n}$ & 42 & 76 & 75 & 193 & \\
\hline \multirow{2}{*}{$\begin{array}{l}\text { It is for me of great personal importance to } \\
\text { study human medicine }\end{array}$} & 5.36 & 5.51 & 5.40 & 5.43 & n. s. \\
\hline & $(0.96)$ & $(0.77)$ & $(0.97)$ & $(0.89)$ & $(F(2,190)=0.46, p=0.63)$ \\
\hline \multirow{2}{*}{$\begin{array}{l}\text { I prefer to talk about the content of my } \\
\text { study subject than about others subjects }\end{array}$} & 3.33 & 3.38 & 3.21 & 3.30 & n. s. \\
\hline & $(0.85)$ & $(1.20)$ & $(1.07)$ & $(1.08)$ & $(F(2,190)=0.45, p=0.64)$ \\
\hline \multirow{2}{*}{$\begin{array}{l}\text { I deal intensively with certain questions of } \\
\text { my studies, also independent of examination } \\
\text { requirements }\end{array}$} & 3.79 & 4.01 & 3.67 & 3.83 & n. s. \\
\hline & $(1.03)$ & $(0.98)$ & $(1.30)$ & $(1.13)$ & $(F(2,190)=1.85, p=0.16)$ \\
\hline \multirow{2}{*}{$\begin{array}{l}\text { I chose my current study mainly because } \\
\text { of the interesting topics }\end{array}$} & 5.00 & 5.10 & 4.73 & 4.94 & n. s. \\
\hline & $(1.04)$ & $(1.01)$ & $(1.28)$ & $(1.13)$ & $(F(2,190)=2.14, p=0.12)$ \\
\hline \multirow[t]{2}{*}{ My interest in biochemistry is very high } & 3.57 & 3.57 & 3.45 & 3.53 & n. s. \\
\hline & $(1.09)$ & $(1.22)$ & $(1.23)$ & $(1.19)$ & $(F(2,190)=0.22, p=0.80)$ \\
\hline \multirow[t]{2}{*}{ My motivation to learn biochemistry is very high } & 3.50 & 3.56 & 3.33 & 3.46 & n. s. \\
\hline & $(1.04)$ & $(1.23)$ & $(1.30)$ & $(1.22)$ & $(F(2,190)=0.68, p=0.51)$ \\
\hline
\end{tabular}

The items were rated by the students on a Likert-type scale from 1 (strongly disagree) to 6 (strongly agree). SD standard deviation, n.s. not significant. Between group comparisons were carried out with ANOVAs

knowledge, compared to students in the basic and individual groups (Fig. 2a; both $p<0.00001$ ). The acquisition of knowledge did not differ significantly between the students in the basic and individual group, nor between conceptual and conditional knowledge. The highest knowledge difference was observed with respect to conditional knowledge between the basic and the collaborative as well as the individual and the collaborative group (Fig. 2a; both $p<0.00001$ ).

An analysis of the single knowledge tests revealed the same differences (Fig. $2 b$ and c). In addition, students from the individual group also experienced a significant better acquisition of knowledge compared to the students in the basic group: in self-study phase 1 this was conceptual (Fig. 2b; $p=0.0474$ ) and in self-study phase 2 conditional knowledge (Fig. 2c; $p=0.0118$ ).

Given the fact that almost all participants prepared for the on-site phases, this data implies that instructions regarding the learning behavior of students (here: individual vs. collaborative) have a greater influence on the learning outcome than the learning material that is provided for the self-study phase.

\section{Collaborative dyadic learning is more than teaming up with a knowledgeable partner}

One possible explanation for the observed effect of superior collaborative preparation could be that dyads of students in the collaborative learning approach perform better because one of the students is more knowledgeable than the other, thereby affecting the learning outcome of the less knowledgeable student. In this scenario, the effect would be due to improved learning of the less knowledgeable member. To test this hypothesis, we generated all possible dyads of participants of students of the individual group $\left(76^{*} 75 / 2=2850\right.$ possible dyads) and took the performance of the more knowledgeable member in the tests to be the performance of this pair. We then performed an analysis by generating artificial groups of equal size and bootstrap estimated the mean performance of the hypothetical groups generated in this way [36]. The procedure was repeated one million times and the distribution of outcomes was plotted and compared to the means of points achieved in the tests of the individual and collaborative groups (Fig. 3).

This data indicates that the overall learning outcome of the participants in the collaborative group cannot be explained solely by the aforementioned hypothesis. If one considers all of the questions in both tests, the probability of a random group of students performing as suggested above and achieving the same or higher total points in the knowledge tests is only $4 \%$ (Fig. 3a; $p=0.042852$ ). If one analyzes the questions in more detail, it becomes clear that this effect is only due to questions that test conditional knowledge (Fig. $3 \mathrm{~A}, \mathrm{~B}, \mathrm{C}$, right panels). The probability that the outcome of the test can be explained by the aforementioned hypothesis in this case is less than $0.0095 \%$ for both tests (Fig. 3a, right panel; $p=9.5 \mathrm{e}-05$ ).

This data indicates that the observed effect on learning outcomes, in particular with respect to conditional knowledge, entails more than teaming up a more knowledgeable with a less well-trained student, and that both students benefit from collaborative learning. This leads to the assumption that additional effects, such as increased motivation and interest or time on task, contribute to a better outcome of the test, something that we therefore tested next. 


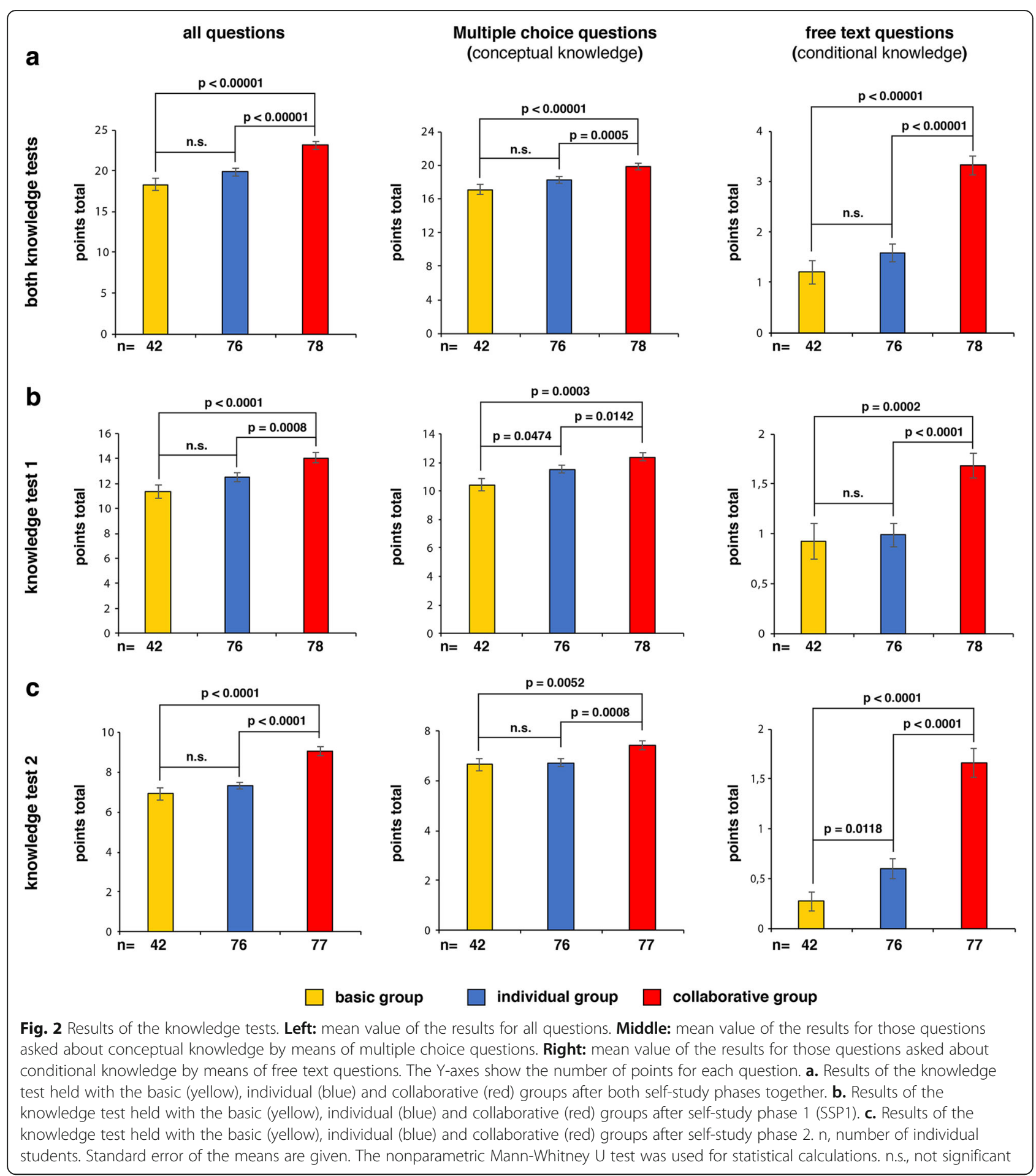

\section{Collaborative dyadic learning stimulates students` motivation and interest}

In order to analyze the students' motivation and their interest in biochemistry during the self-study phases, we asked about I) the students` learning motivation, II) their recognition of its relevance for their medical studies or their professional life, and III) their interest in biochemistry (Fig. 4).

In self-study phase 1 , the participants in individual and collaborative groups exhibited a significantly higher motivation to learn compared to the basic group (all $p<0.01$ ) (Fig. 4a). With respect to their 


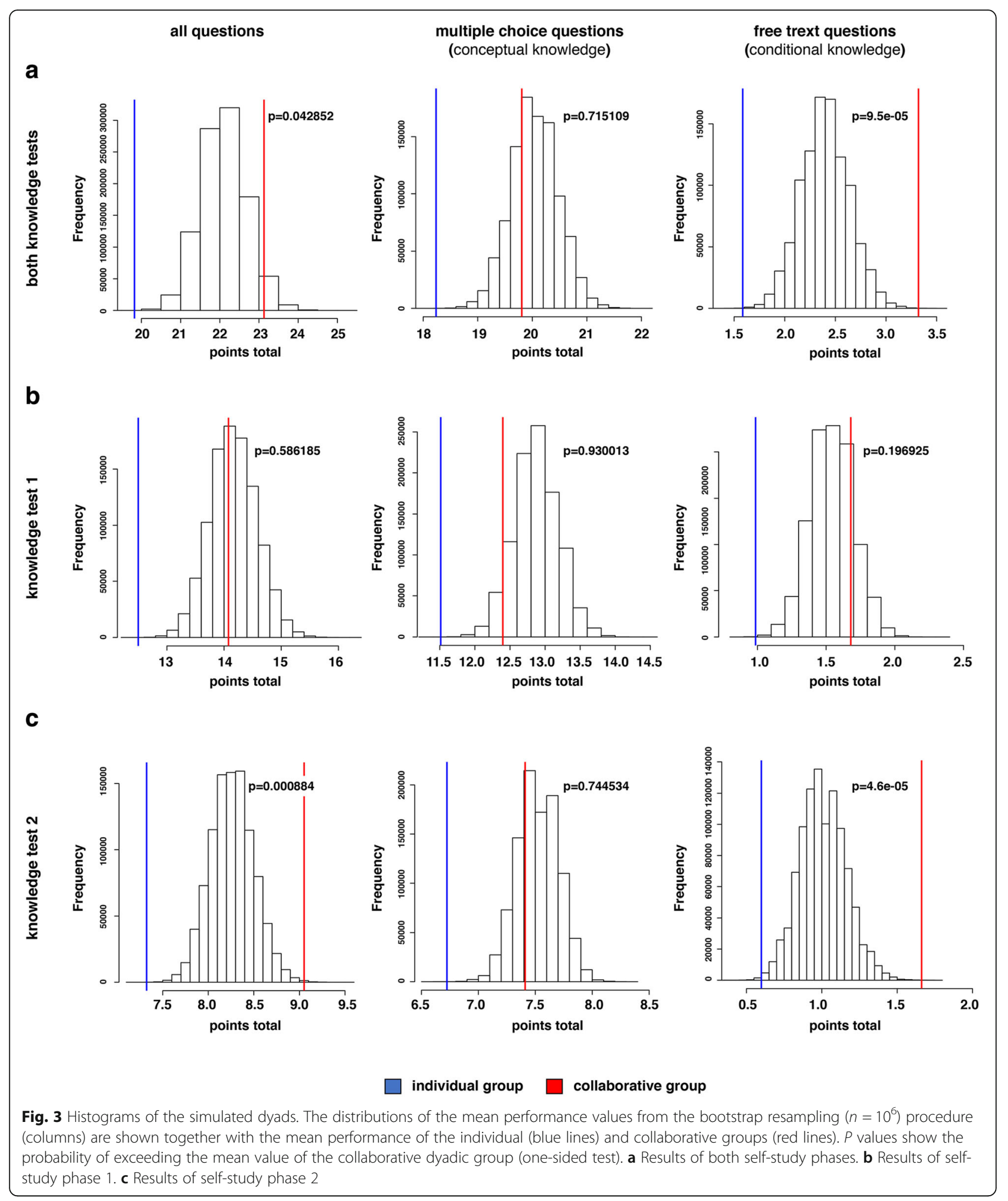

recognition of its relevance for their professional life, the collaborative group scored higher than the individual group $(p=0.008)$.
In self-study phase 2, the collaborative group scored higher than the basic group in every respect (all $p<0.05$ ), were more motivated to learn than the individual group 

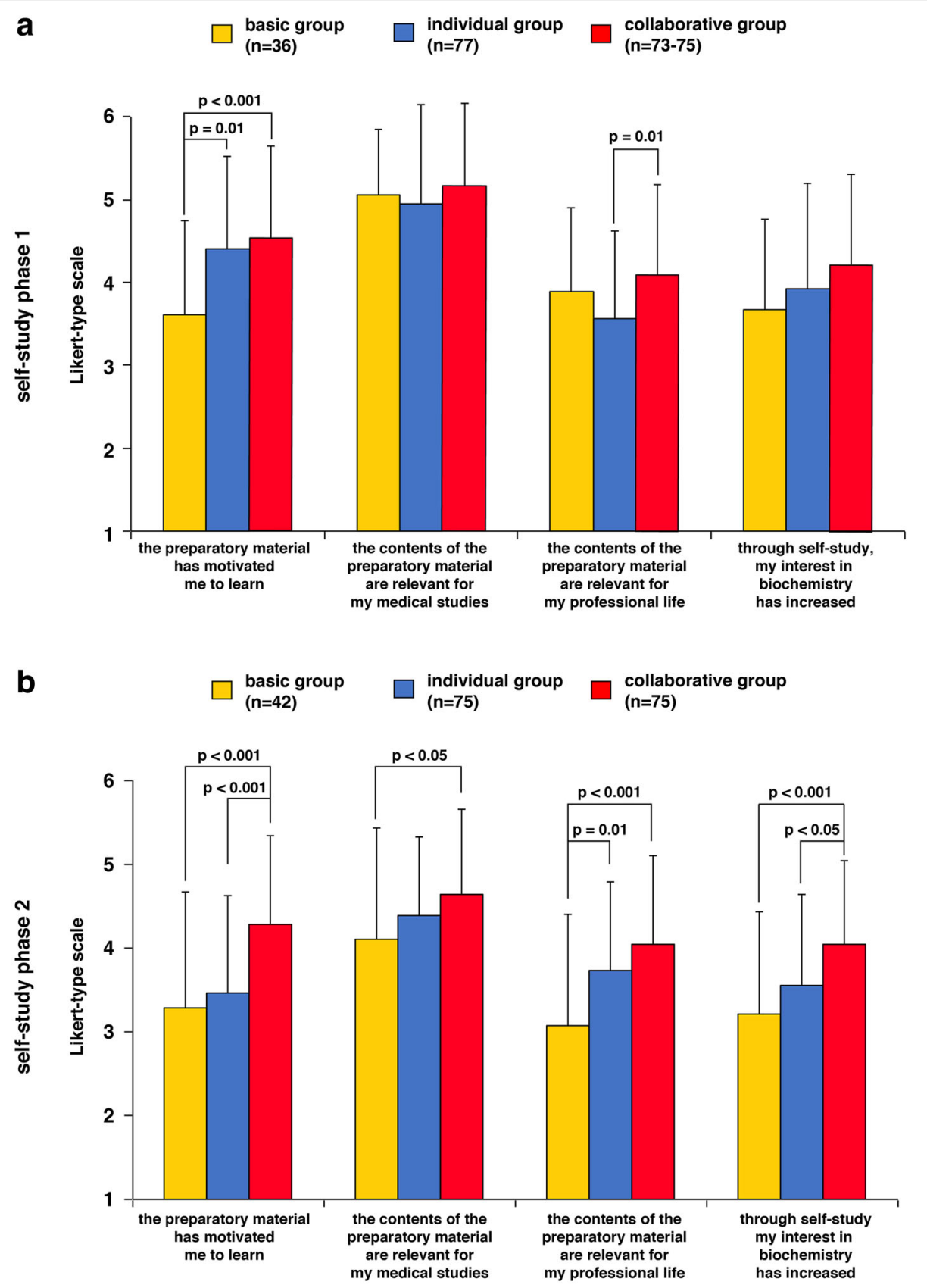

Fig. 4 Questionnaires about the preparatory material and interest in the self-study phases. The items were rated by the students on the basis of a Likert-scale from 1 (strongly disagree) to 6 (strongly agree). a. Results of self-study phase 1. b. Results of self-study phase 2. n, number of individual students. Standard deviations are given. Analyses were carried out with ANOVAs between groups, Tukey-HSD was used for post hoc comparisons

$(p<0.001)$ and received a higher score in terms of an increased interest through the self-study phase $2(p=0.016)$. The individual group achieved higher values than the basic group with respect to their recognition of its relevance for their professional life $(p=0.008)$ (Fig. 4b).

Taken together, our data indicates that collaborative dyadic learning in the self-study phase increases motivation and an interest in the topic.
Collaborative dyadic learning affects the time on task

We also asked about the preparation time in the self-study phases to check for possible differences in learning outcomes between the different study groups (Fig. 5). In self-study phase 1, students in the basic group learned for a shorter period of time than students in the individual and collaborative groups $(p=0.008$ and $p=0.003)$. In contrast, the learning time in the 


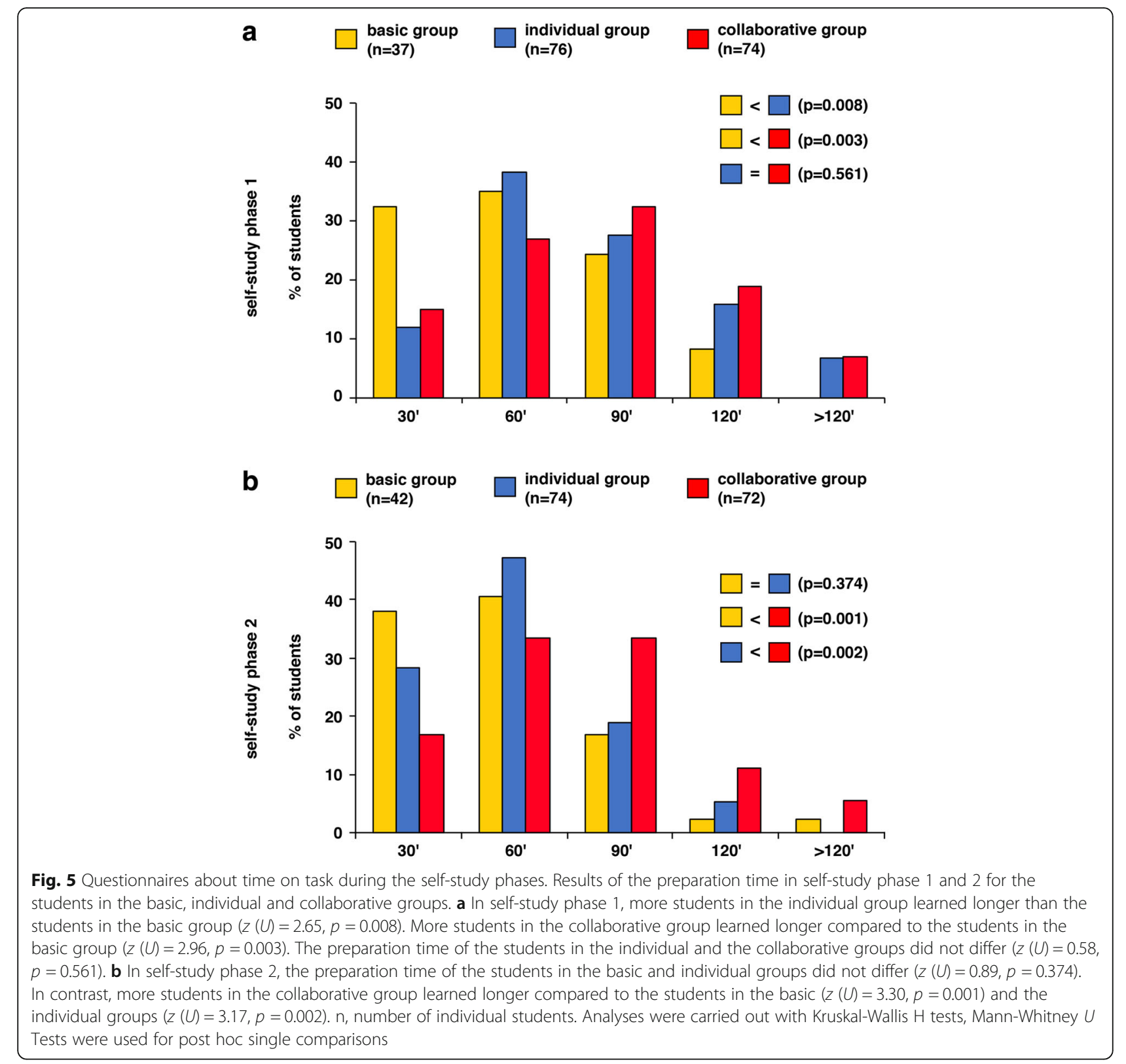

individual and collaborative groups did not differ significantly $(p=0.561)$. In self-study phase 2 , the learning time in the basic and individual groups did not differ $(p=0.374)$. However, students in the collaborative group prepared for longer than students in the basic $(p=$ $0.001)$ and individual $(p=0.002)$ groups.

In summary, students in the collaborative group spent more time on the task than the other groups.

\section{Discussion}

The data obtained from our study for the first time revealed that there is a significant difference in the learning success within an e-learning-based IC approach depending on the learning instructions. Students who were instructed to learn in a dyad (collaborative) were more successful than students who learned individually. In contrast, we discovered a somewhat minor difference in the learning success depending on the learning material provided, as shown by the comparison between the basic and individual groups.

\section{Learning material for the self-study phase in an inverted classroom setting}

We tested the effect of different learning materials on the learning success of students in the self-study phase of the IC. Whereas the basic group were only told to study educational videos, the individual group (as well as the collaborative group) received additional study 
material including comprehension questions. There was only minor difference between preparation with comprehension questions (individual group) and preparation without comprehension questions (basic group) with respect to the acquisition of both conceptual and conditional knowledge, measured by knowledge tests at the beginning of the on-site phases 1 and 2. A positive effect of the study material on the learning outcome might be obscured in our study. However, since almost all of the students prepared for the on-site phases 1 and 2, this might already indicate a great interest of students in this learning approach. Moreover, the videos may have presented the subject matter in a manner such that the additional study material did not add any significant information. In cases where this cannot be guaranteed, the study material might have a greater impact.

\section{Learning instruction: collaborative learning as a powerful tool in the self-study phase of an e-learning-based inverted classroom}

We were able to show that the learning process in the self-study phase in an IC is dependent upon the instruction given on how to organize the self-study phases. Students who were told to learn with a learning partner were more successful in remembering and applying the content of the self-study phases in the knowledge tests after the self-study phases than students who learned individually. The same effect could also be observed with respect to the conceptual and conditional knowledge. Since almost all of the participants (basic, individual, collaborative group) prepared for the on-site phases 1 and 2, this data implies that instructions regarding the learning behavior of students (here: individual vs. collaborative) have a greater influence on the learning outcome than simply providing additional learning material for the self-study phase.

In short, collaborative preparation in the self-study phase is much more effective than individual preparation. This is not all that surprising as it has already been shown that collaborative learning, such as asking each other questions or explain things to each other (students had to perform both of these tasks in our self-study phases) is presumed to encourage learning [37]. From a socio-cognitive point of view, learning is a change in cognitive structures that consists of new connections being made between new information and prior knowledge, whereby the new information is integrated into the participants' existing knowledge [38]. According to Vygotsky (1978), this process is greatly affected by interaction and the way activity takes place.

Although research has already shown that several types of collaborative learning activities foster learning, these activities rarely occur in collaborative processes without any structuring of the interaction [37, 39, 40].
Different terms are used in educational literature for structuring interactions such as prompting thinking, scaffolding learning or guiding cognitive performance, to name but a few.

One term that is used more often in combination with computer-supported collaborative learning (CSCL) is scripted collaboration. The term script goes back to Schank and Abelson (1977), who viewed the term script as an internal memory structure of a "sequence of actions that define a well-known situation" (p. 41) [41]. Whereas Schank and Abelson (1977) viewed the term script as being relatively static, the educational view of the term script (or scripting) describes it as being externally imposed, more flexible and with a broader application. Scripting collaboration describes externally structured collaborative learning that prompts group interaction, which in turn fosters learning [42-44]. To begin with, the script is imposed on the individual and is therefore considered to be external. Over time and with practice, it will become internalized, following Vygotsky (1978), and therefore can be called an internal collaboration script.

Fischer and colleagues outlined a script theory of guidance for CSCL, which is based on four script components (play, scene, role and scriptlet). These differ with respect to their cognitive target level and seven principles [30]. Their script theory of guidance describes the use of internal scripts, the configuration and reconfiguration of internal scripts and the transfer from external to internal scripts within the seven principles. The theory also describes the advantages of external scripts and states when they are most effective for knowledge acquisition.

In our study, we used script components (play and scene) according to Fischer et al. (2013) to guide the students in the individual and collaborative groups through the self-study phases [30]. It would be interesting to discover whether the learning success of students could be further improved by forming small learning groups and using all four script components in the self-study phases of an IC in future studies. This could be achieved, for example, by setting up closed, virtual interaction rooms and assigning different roles and functions to the participating students. Consequently, collaborative learning in the self-study phase of an IC approach would be taken to the next level, thus allowing more complex interactions between participants.

\section{Possible reasons for the efficiency of collaborative dyadic learning on learning success}

In order to investigate the reason for the better learning success with collaborative dyadic learning, we formed all possible pairs of students of the individual group and used the outcome of the more knowledgeable member 
as the outcome of this pair. This data revealed that the positive effect of collaborative learning is not due solely to one of the students being more knowledgeable than the other, thus affecting the learning outcome of the less knowledgeable student. Rather, our data shows that both students benefit from one another. This data is in line with other studies, which showed that medical students working in pairs have a better diagnostic performance and this also helps to reveal gaps in knowledge $[45,46]$. Dyadic working was also shown to be very efficient for solving mathematical problems, in software development (e.G. agile software development and extreme programming) or when learning a foreign language in particular [47-50].

Furthermore, we observed an increase in motivation, interest and recognition of relevance as well as in the length of time on task amongst dyadic learners. This data indicates that the study material, including the comprehension questions, together with the instruction to learn collaboratively, may have a positive effect on motivation and interest. In some respects, students in the individual group showed much more motivation compared to students of the basic group. This demonstrates that the on-site phase 0 may already induce a greater motivation amongst students to prepare for the on-site phase, though this needs to be investigated in more detail in a follow-up study. Moreover, the instruction to prepare collaboratively results in an increase in the number of students who learned in dyads. This effect could be maintained in the second self-study phase, indicating that either the students appreciated this kind of learning or that medical students in the second semester followed the lecturer's instructions.

\section{Combination of the inverted classroom with collaborative learning for competency-based training}

In a previously published study, we already revealed the benefits of the inverted classroom method for competency-based training [3]. We demonstrated that the freed-up time in the on-site phase can be used to teach competency-orientated learning objectives such as communication in a team or with peers or laymen (medical communication). This was extended in the present investigations to the self-study phase because the collaborative learning approach encourages the mediation of competency-based learning objectives in the following ways. First, the students were actively instructed to form a learning dyad in a self-directed manner, this fostering independent, self-organized team working. Second, the students had to explain the different learning contents to each other. The listeners were allowed to ask for more details, this being tantamount to a simulation of an explanatory meeting with a patient. Third, the students had to cope with problem-solving tasks, a key competency in the correct diagnosis of diseases. Interestingly enough, the positive effect of the collaborative learning method became particularly clear in the problem-solving tasks of the knowledge tests (asking for conditional knowledge). We saw a very significant difference in learning success between collaborative learners and individual learners. Our results support the findings of Hautz and colleagues, who already highlighted the success of pair work in the performance of diagnoses by medical students [45].

\section{Problem-solving tasks: a powerful instrument to test competency-based learning objectives?}

As explained above, the efficacy of dyadic learning could be especially observed in the problem-solving tasks of the knowledge tests (conditional knowledge). Testing competency-based learning objectives calls for appropriate exams and the integration of problem-solving tasks could be one possible solution. The problem, however, is an objective evaluation of student's free text answers. Since most universities have to deal with quite a large number of medical students each year, the restricted number of teachers will not be able to solve this problem. One possibility could be the implementation of a computer-based/electronic evaluation of free text answers. This is, however, problematic in the case of handwritten answers, which would require character recognition methods for handwritten symbols. Moreover, semantic information extraction systems would have to be developed, e.g. by using deep learning approaches, though these require large corpora of training data [51]. It would be more realistic to develop e-based examinations with long menu options that could be modified and further adapted to allow the possibility of providing free text answers.

\section{Limitations of the study}

The main limitation of our study is the fact that only $64 \%$ (self-study phase 1) and $58.7 \%$ (self-study phase 2 ) of students actually prepared in a learning dyad as instructed in the collaborative study group. Nevertheless, we decided to analyze and integrate the data for all students in the collaborative group because this reflects how students follow the teachers` instructions and provides teachers with a more realistic picture of what might be expected from this kind of instruction. The strength of our findings is therefore somewhat underestimated, suggesting that the more students learn in dyads, the better their learning outcome will be.

In our present study, we compared three different study groups. An additional study group with an on-site phase 0 and educational videos as study material, but no comprehension questions in the self-study phases, may have been of interest. We did in fact try to organize such 
a group. Unfortunately, we were unable to include this data in our analysis because only a very limited number of students attended the on-site phase 0 .

Further limitations of the study are that it is a mono-institutional study and that two lecturers are also investigators of the study. Therefore, it would be interesting to replicate this study in another institution and another field of medical education with independent lecturers.

\section{Conclusion}

Our study indicates that the study material and, more importantly, the instructions provided for the self-study phase, affect the success of an e-learning-based inverted classroom. Instructed collaborative dyadic learning had the highest success rate in the learning outcome. It would be interesting to investigate whether the learning success of students could be further improved by forming small learning groups for the self-study phase in the future. Furthermore, a stable electronic evaluation of free text answers should be established to provide a good instrument to test competency-based learning objectives.

\section{Additional files}

Additional file 1: Overview of the study design. (JPG $786 \mathrm{~kb}$ )

Additional file 2: Supplementary Material. (DOCX $17 \mathrm{~kb}$ )

\section{Abbreviations}

IC: Inverted classroom; n: Number of individual students; SDS-PAGE: Sodiumdodecylsulfate polyacrylamide gelelectrophoresis

\section{Acknowledgements}

We would like to thank Stefanie Hauser (Würzburg University, Germany) and Stefanie Oess (Frankfurt University, Germany, now Brandenburg Medical School Theodor Fontane, Germany) for their critical review of the knowledge tests and the comprehension questions in the study material for the selfstudy phases. We would also like to thank Stefanie Hauser (Würzburg University, Germany) for reviewing the educational videos and Ruth Lagies (Bonn University, Germany) and Ursula Kriesen (Rostock University, Germany) for reviewing clinical contents. Our thanks to Petra Pandur and Ivonne Sehring, both Ulm University, for participating as lecturers during this study. Furthermore, we would like to thank Helen Tauc (Gentech, USA) and Michael Schmeisser (Magdeburg University, Germany) for their critical reading of the manuscript.

\section{Funding}

The project was supported by the Medical Faculty of UIm University with funds from the "Sonderlinie Medizin" of the State of Baden-Württemberg, Germany. This project was part of the Master of Medical Education (MME) training program of S.J.K., which was also financially covered by the Medical Faculty of Ulm University.

\section{Availability of data and materials}

The datasets and materials used and/or analyzed during the current study are available from the corresponding author on reasonable request.

\section{Authors' contributions}

SJK, MK, and MF designed the study and discussed the analysis and results. SJK, MT, and MK prepared the educational videos. SJK prepared the study material for the self-study phases and developed the tests taken at the beginning of the on-site phases. MK commented on study materials and tests. AS commented on study materials. SJK prepared the questionnaires completed at the beginning of the on-site phases. AS commented on the questionnaires. SJK introduced students to the IC method. SJK and MK taught during the on-site phases of the course. SJK evaluated the knowledge tests. MK performed a cross check. SJK performed the statistical analysis. SJK and AS evaluated the questionnaires. AS performed the statistical analysis with diagrams. HAK programmed and performed the bootstrap analysis with diagrams. SJK prepared all of the figures, AS prepared the tables. SJK, MK, and AS wrote the first draft of the paper. All authors commented on further versions of the manuscript. All authors read and approved the final manuscript.

\section{Ethics approval and consent to participate}

The ethics committee of Ulm University confirmed that no approval was required for this study. We affirm that we obtained verbal informed consent from all participants in this study.

Consent for publication

Not applicable.

\section{Competing interests}

The authors declare that they have no competing interests.

\section{Publisher's Note}

Springer Nature remains neutral with regard to jurisdictional claims in published maps and institutional affiliations.

\section{Author details}

${ }^{1}$ Institute of Biochemistry and Molecular Biology, Ulm University, Albert-Einstein-Allee 11, 89081 Ulm, Germany. ${ }^{2}$ Office of the Dean of Studies, Medical Faculty, Ulm University, 89081 Ulm, Germany. ${ }^{3}$ Institute of Medical Systems Biology, Ulm University, 89081 Ulm, Germany. ${ }^{4}$ Institute for Medical Education, University Hospital, LMU Munich, 80336 Munich, Germany.

Received: 23 November 2017 Accepted: 15 February 2019

Published online: 28 February 2019

\section{References}

1. Johnson L, Adams Becker S, Estrada V, Report FANMCH. Higher education edition. Austin New Media Consort. 2014:2014.

2. Lage MJ, Platt GJ, Treglia M. Inverting the classroom: a gateway to creating an inclusive learning environment. J Econ Educ. 2000;31:30-43.

3. Kühl S, Toberer M, Keis O, Tolks D, Fischer M, Kühl M. Concept and benefits of the inverted classroom method for a competency-based biochemistry course in the pre-clinical stage of a human medicine course of studies. GMS. J Med Educ. 2017:34.

4. O'Flaherty J, Phillips C. The use of flipped classrooms in higher education: a scoping review. Internet High Educ JAl. 2015;25:85-95.

5. Street SE, Gilliland KO, McNeil C, Royal K. The flipped classroom improved medical student performance and satisfaction in a pre-clinical physiology course. Med Sci Educ Springer US; 2015;25:35-43.

6. Tune JD, Sturek M, Basile DP. Flipped classroom model improves graduate student performance in cardiovascular, respiratory, and renal physiology. AJP Adv Physiol Educ. 2013;37:316-20.

7. Bösner S, Pickert J, Stibane T. Teaching differential diagnosis in primary care using an inverted classroom approach: student satisfaction and gain in skills and knowledge. BMC Med Educ. 2015:15:63.

8. Morgan H, McLean K, Chapman C, Fitzgerald J, Yousuf A, Hammoud M. The flipped classroom for medical students. Clin Teach. 2015;12:155-60.

9. Bohaty BS, Redford GJ, Gadbury-Amyot CC. Flipping the classroom: assessment of strategies to promote student-centered, self-directed learning in a dental school course in pediatric dentistry. J Dent Educ. 2016;80:1319-27.

10. Ferreri SP, O'Connor SK. Redesign of a large lecture course into a smallgroup learning course. Am. J. Pharm. Educ. American Association of Colleges of Pharmacy. 2013;77:13.

11. McLaughlin JE, Roth MT, Glatt DM, Gharkholonarehe N, Davidson CA, Griffin LM, et al. The flipped classroom: a course redesign to foster learning and engagement in a health professions school. Acad Med. 2014;89:236-43. 
12. Pierce R, Fox J. Vodcasts and active-learning exercises in a \&quot;flipped classroom\&quot; model of a renal pharmacotherapy module. Am J Pharm Educ American Association of Colleges of Pharmacy. 2012;76:196.

13. Critz CM, Knight D. Using the flipped classroom in graduate nursing education. Nurse Educ. 2013;38:210-3.

14. Missildine K, Fountain R, Summers L, Gosselin K. Flipping the classroom to improve student performance and satisfaction. J Nurs Educ. 2013;52:597-9.

15. Gilboy MB, Heinerichs S, Pazzaglia G. Enhancing student engagement using the flipped classroom. J Nutr Educ Behav. 2015;47:109-14.

16. Lake DA. Student performance and perceptions of a lecture-based course compared with the same course utilizing group discussion. Phys Ther. 2001; 81:896-902.

17. Prober CG, Khan S. Medical education reimagined: a call to action. Acad Med. 2013;88:1407-10.

18. Ojennus DD. Assessment of learning gains in a flipped biochemistry classroom. Biochem Mol Biol Educ. 2016;44:20-7.

19. Harrel KM. Enhancing active learning in a medical gross anatomy and embryology course: a flipped classroom approach. FASEB J. 2016;30.

20. Curran S, Royer D. Student attitudes toward a flipped classroom Design for Circulatory System in medical school gross anatomy. FASEB J. 2017;31.

21. Gutmann J, Kühbeck F, Berberat PO, Fischer MR, Engelhardt S, Sarikas A. Use of learning media by undergraduate medical students in pharmacology: a prospective cohort study. PLoS One. 2015;10:e0122624.

22. Felder $\mathrm{E}$, Fauler M, Geiler S. Introducing e-learning/teaching in a physiology course for medical students: acceptance by students and subjective effect on learning. PLoS One. 2013;37:337-42.

23. Cabrera AF, Nora A, Crissman JL, Terenzini PT, Bernal EM, Pascarella ET. Journal of college student development. J. Coll. Stud. Dev. American College Personnel Association. 2002.

24. Johnson DW, Johnson RT, Smith KA. Cooperative learning returns to college what evidence is there that it works? Chang Mag High Learn Taylor \& Francis Group. 1998:30:26-35.

25. Kalaian SA, Kasim RM. Effectiveness of various innovative learning methods in health science classrooms: a meta-analysis. Adv Heal Sci Educ. 2017;22: $1151-67$.

26. Slavin RE. Cooperative learning : theory, research, and practice: Allyn and Bacon; 1994

27. Hänze M. Was bringen kooperative Lernformen? Ergebnisse aus der empirischen Lehr-Lern- Forschung. Friedrich Jahresh. XXVI. Seelze: Friedrich Verlag; 2008. p. 24-25.

28. Kooloos JGM, Klaassen T, Vereijken M, Van Kuppeveld S, Bolhuis S, Vorstenbosch M. Collaborative group work: effects of group size and assignment structure on learning gain, student satisfaction and perceived participation. Med Teach. 2011;33:983-8.

29. Kollar I, Fischer F, Hesse FW. Collaboration scripts - a conceptual analysis. Educ Psychol Rev. 2006;18:159-85.

30. Fischer F, Kollar I, Stegmann K, Wecker C. Toward a script theory of guidance in computer-supported collaborative learning. Educ Psychol. 2013; 48:56-66.

31. Schmidmaier R, Eiber S, Ebersbach R, Schiller M, Hege I, Holzer M, et al. Learning the facts in medical school is not enough: which factors predict successful application of procedural knowledge in a laboratory setting? BMC Med. Educ. 2013;13:28.

32. Stark R, Kopp V, Fischer MR. Case-based learning with worked examples in complex domains: two experimental studies in undergraduate medical education. Learn Instr Pergamon. 2011;21:22-33.

33. Bloom BS, Krathwohl DR, Masia BB. Taxonomy of educational objectives. New York: D. McKay; 1956.

34. Anderson LW, Krathwohl DR, Bloom BS. Taxonomy for learning, teaching, and assessing a revision of Bloom's taxonomy of educational objectives. New York. NY: Longman; 2001.

35. Team RDC. R: a language and environment for statistical computing. Vienna: the: R Foundation for Statistical Computing; 2017.

36. Efron B, Tibshirani RJ. An introduction to the bootstrap. New York: Chapman Hall; 1993.

37. Webb NM. Peer interaction and learning in small groups. Int J Educ Res Pergamon. 1989;13:21-39.

38. Vygotsky L, Kozulin R. Mind in society : the development of higher psychological processes: Harvard University Press; 1978.

39. Weinberger A, Fischer F, Mandl H. Fostering computer supported collaborative learning with cooperation scripts and scaffolds. Proc Conf
Comput Support Collab Learn Found a CSCL Community International Society of the Learning Sciences. 2002:573-4.

40. Weinberger A, Stegmann K, Fischer F, Mandl H. Scripting argumentative knowledge construction in computer-supported learning environments. Scripting Comput. Collab. Learn. Boston, MA: Springer US; 2007. p. 191-211.

41. Abelson R, Schank RC. Scripts, plans, goals and understanding, an inquiry into human knowledge structures. J Pragmat North-Holland. 1979;3:211-7.

42. Hämäläinen $\mathrm{R}$, Oksanen $\mathrm{K}$, Häkkinen P. Designing and analyzing collaboration in a scripted game for vocational education. Comput Human Behav. 2008;24:2496-506.

43. Schellens $T$, Van Keer H, De Wever B, Valcke M. Scripting by assigning roles: does it improve knowledge construction in asynchronous discussion groups? Int. J. Comput. Collab. Learn. 2007;2:225-46.

44. Schoonenboom J. The effect of a script and a structured interface in grounding discussions. Int J Comput Collab Learn. 2008:3:327-41.

45. Hautz WE, Kämmer JE, Schauber SK, Spies CD, Gaissmaier W. Dlagnostic performance by medical students working individually or in teams. J Am Med Assoc. 2015;313:303-4.

46. Elzie C, Goodmurphy CW. The benefits of pair-share concept mapping in anatomy and embryology. FASEB J. 2017.

47. Kwok AP, Lau A. An exploratory study on using the think-pair-share cooperative learning strategy. J Math Sci. 2015:2:22-8.

48. Beck K. Extreme programming explained : embrace change: AddisonWesley; 2004

49. Beck K, Grenning J, Martin RC, Beedle M, Highsmith J, Mellor S, et al. Manifesto for agile software. Development. 2001

50. Anggraini K, Nurweni A, Suparman U. The comparison of collaborative learning techniques: think-pair-share and co Op - co Op in improving students' descriptive writing. U-JET. 2017;6.

51. Goodfellow I, Bengio Y, Courville A. Deep learning. In: MIT press; 2016.

\section{Ready to submit your research? Choose BMC and benefit from:}

- fast, convenient online submission

- thorough peer review by experienced researchers in your field

- rapid publication on acceptance

- support for research data, including large and complex data types

- gold Open Access which fosters wider collaboration and increased citations

- maximum visibility for your research: over $100 \mathrm{M}$ website views per year

At BMC, research is always in progress.

Learn more biomedcentral.com/submissions 